\title{
É possivel uma história da historiografia medieval?
}

\author{
İs a history of medieval historiography possible?
}

\author{
Rodrigo Prates de Andrade ${ }^{a}$ \\ E-mail: andrade.rprates@gmail.com \\ https://orcid.org/0000-0003-1787-6191
}

a Universidade Federal de Santa Catarina, Departamento de História, Programa de Pós-Graduação em História, Florianópolis, SC, Brasil

\section{RESUMO}

Neste artigo, ao tomar como ponto de partida uma possível dubiedade da historiografia medieval, nos propomos a refletir sobre as limitações de uma episteme temporal e espacialmente centrada na Europa e na modernidade, além de traçar alguns caminhos possíveis à compreensão dos modos de historicização medievais. Essas reflexões possuem como princípio um debate alavancado pela historiografia francesa da segunda metade do século $X X$ acerca da existência de uma fratura entre modernos e pré-modernos, que impediria uma percepção acurada das experiências humanas do passado a partir de um vocabulário guiado pela modernidade. Nessa perspectiva, o próprio conceito moderno de história, fruto dos séculos XVIII e XIX, seria incapaz de apreender modos de produzir e representar o passado anteriores a sua concepção. A fim de responder tais questionamentos, procuramos traçar outras possibilidades de compreensão dos conceitos de história e historiografia através de uma aproximação entre os estudos medievais, a história da historiografia e a antropologia. As considerações estabelecidas aqui buscam reafirmar demandas atuais da história disciplinar, ao mesmo tempo que aventam uma abertura da história da historiografia como um meio de abarcar os múltiplos modos de historicização pré-modernos e não ocidentais.

\section{PALAVRAS-CHAVE}

História da historiografia; História Medieval; Antropologia

\section{ABSTRACT}

Starting from a possible dubiousness of medieval historiography, this article reflects on the limitations of a temporal and spatial episteme centered on Europe and modernity; furthermore, we trace some possible ways to understand medieval modes of historicization. These discussions are based on a debate leveraged by the French historiography of the second half of the 20th century about the existence of a divide between moderns and pre-moderns that would prevent an accurate perception of the human experiences of the past from a vocabulary guided by modernity. In this perspective, the very modern concept of history - fruit of the 18th and 19th centuries - would be unable to grasp ways of producing and representing the past prior to its conception. To answer these questions, we look to trace other possibilities for understanding the concepts of history and historiography by bringing together the medieval studies, the history of historiography, and anthropology. The considerations established here seek to reaffirm the current demands of disciplinary history, while also suggesting an opening of the history of historiography as a means of embracing the multiple pre-modern and non-Western modes of historicization.

\section{KEYWORDS}

History of historiography; Medieval history; Anthropology 
Em Une histoire religieuse du Moyen Âge est-elle possible?, ensaio publicado em 1994, o medievalista Jean-Claude Schmitt se questionou acerca da possibilidade de uma história religiosa do medievo. Uma questão que, segundo o próprio autor, poderia parecer estranha aos olhos e ouvidos contemporâneos, afinal foram aqueles mesmos séculos conhecidos pela presença constante da fé. No entanto, esse questionamento carrega em seu âmago outra face: o conceito de religião é conveniente à compreensão do cristianismo medieval? Nas palavras de Schmitt, "o recuo que se impõe à antropologia que estuda uma sociedade diferente da sua não é ainda mais indispensável para o historiador cujo objeto de estudo é a tradição à qual pertence?" (SCHMITT 2014, p. 31).

Não procuramos aqui, como demonstra o título deste ensaio, acercar-nos sobre os estudos das práticas "religiosas" na Idade Média. Contudo, ao refletirmos sobre a viabilidade de uma história da historiografia medieval, os questionamentos de Schmitt complexificam nossos problemas: se a história, objeto e ofício dos historiadores na contemporaneidade, está arraigada em nossas percepções, ela é conveniente ao exame das formas de experienciar o tempo no medievo? Crônicas, hagiografias, genealogias e outros gêneros de narração sobre o passado circularam entre mosteiros e cortes na cristandade latina medieval. Seria possível classificarmos esta profusão de obras sob o signo da história?

Nas palavras de historiadores como Bernard Guenée (GUENÉE 1980, p. 11) e Justin Lake (LAKE 2015, p. 89), por muitos anos aqueles que se debruçavam nesses gêneros "historiográficos" procuravam modos de "encontrar o passado" - como se aqueles documentos se transmutassem em "janelas" para outras temporalidades -, a desconsiderar intenções, formas de compreender o mundo e contextos sociais. Eles se constituíam como documentos capazes de fornecer informações aos historiadores sobre os aspectos aos quais versavam. Por outro lado, como aponta 
Lake, em Current Approaches to Medieval Historiography, pesquisas recentes buscaram observar nesses textos não apenas "fatos" sobre o passado, mas as modalidades pelas quais foram compostos. Um eco da ideia de que o passado, ou ao menos sua escrita, configurava-se a partir dos anseios do presente, afirmação reconhecida por parte considerável do campo disciplinar no âmbito da historiografia moderna e que justamente incidiria de maneira similar naquilo que podemos chamar de uma "historiografia medieval" (LAKE 2015, p. 89).

Para Bernard Guenée, ao menos nos círculos franceses, os estudos voltados à compreensão de uma "historiografia medieval" deram seus primeiros passos somente entre os anos de 1866 e 1876, em torno da Revue critique d'histoire et de littérature. Permeada por perspectivas oriundas da ciência histórica alemã, foi nessa mesma revista que a palavra "historiografia", associada à ideia de uma literatura histórica, apareceu pela primeira vez em território francês. Nesse contexto, a própria palavra historiografia concebia múltiplos sentidos, desde "a arte de escrever a história" até a um campo específico destinado à análise de textos históricos, isto é, aquilo que chamamos de história da historiografia (GUENÉE 1980, p. 11-12).

A ambiguidade presente na historiografia, como aponta Guenée, não se limita à compreensão de um campo geral, mas igualmente em suas especificidades. Afinal, quando falamos de uma historiografia medieval, estamos a significar as obras voltadas à produção e representação do passado gestadas em um determinado período histórico, ou a um conjunto de escritos contemporâneos acerca da Idade Média? Para além dessa flutuação semântica, estudiosos tanto do medievo quanto da modernidade apontavam que a ausência dos parâmetros modernos, do que se definia enquanto "historiografia" sustentava a ideia de que entre os "medievais" não teria existido um labor dito "historiográfico" (GUENÉE 1980, p. 12-15). 
Em sua multiplicidade de sentidos e a fim de evitar a reiteração de um discurso que nega o estatuto "historiográfico" aos gêneros medievais de produção e representação do passado baseada em uma tradição moderna, optamos por assumir esses mesmos gêneros a partir do signo de uma "historiografia medieval".

Nossas proposições, cabe ressaltar, não visam a um estudo dessa multiplicidade "historiográfica" no medievo, temática que conta com uma ampla ancoragem nos estudos medievais $^{1}$, mas a uma inquirição dos sentidos da atribuição de um estatuto "historiográfico" para essas obras. Ao tomarmos como ponto de partida uma possível dubiedade da historiografia medieval, nos propomos a refletir sobre as limitações de uma episteme temporal e espacialmente centrada na Europa e na modernidade, além de traçar alguns caminhos possíveis à compreensão dos ditos modos de historicização medievais.

\section{Uma fratura cognitiva}

Ora, segundo Alain Guerreau, o século XVIII estabeleceu uma fratura entre "pré-modernos" e "modernos". Em suas palavras, conceitos como economia e religião, concebidos na modernidade, no intuito de explicá-la, são incapazes de apreender a sociedade medieval. Empregá-los aos estudos dessas sociedades incorreriam em contradições que viciariam a abordagem historiográfica (GUERREAU 2002, p. 21-26). Não seria preciso aqui traçar as aproximações entre Guerreau e Schmitt - a modernidade marcava, em suas perspectivas, uma fratura cognitiva que nos impossibilitaria de compreender um mundo "pré-moderno" a partir de um vocabulário exógeno. Afinal, é possível pensar os modos de crença das sociedades latino-cristãs no medievo por meio da religião?

Em suas ressalvas, Schmitt destacou como o conceito de religião, tal como usualmente o compreendemos, era um fenômeno da modernidade - ele configurava um modo de crer, mas também um papel institucional da Igreja que não
${ }^{1}$ Não poderíamos aqui deixar de referenciar os trabalhos seminais de Bernard Guenée Histoire et culture historique dans I'Occident médiéval (1980) e de Gabrille Spiegel The Past as Text: The Theory and Practice of Medieval Historiography (1997), obras fundamentais ao estabelecimento de uma história da historiografia medieval. 
encontrava eco nos séculos anteriores. Nesse caso, a cultura cristã da modernidade funcionava como um filtro capaz de moldar nossa visão acerca de outras sociedades. Isso ocorreria de tal modo que, quando pensamos no politeísmo grecoromano, acabamos por reproduzir uma lógica própria da Igreja que o opunha ao monoteísmo judaico-cristão. A própria ideia de transcendência divina, componente essencial ao cristianismo, não poderia ser reempregada em outros modos de crença sem incorrer em disfunções (SCHMITT 2014, p. 31-33).

O medievalista, inserido em países como a França, marcados por um vocabulário eurocentrado, deve se despir. Cabem a esses historiadores romper as "continuidades aparentes" que, no espaço e no tempo, os conectam ao seu objeto de estudo. Tal qual o antropólogo, ele deve recuar, desidentificar-se, tanto no âmbito da experiência quanto nas palavras, a fim de evitar a reiteração de um discurso tautológico sobre a Idade Média (SCHMITT 2014, p. 33-35).

Desenvolvida no decorrer da segunda metade do século $X X$, a antropologia histórica francesa se pautou em um procedimento fundamental ao saber antropológico - a desidentificação. As ressalvas do autor acerca da necessidade de um recuo, denotam uma fratura entre o passado e o presente que deveria ser sobreposta pelo historiador. Ao propor um distanciamento, a antropologia histórica, na perspectiva de Schmitt, rompe com um tipo de história que compreendia uma confluência entre o medievo e a modernidade - a existência, por exemplo, de uma religião na Idade Média em moldes similares aos nossos.

No âmbito da historiografia francesa, a aproximação com a ciência social "vizinha" antecedeu à alcunha da antropologia histórica. Se, em Os reis taumaturgos, Marc Bloch já sustentava uma visão interdisciplinar entre os dois campos, foi no decorrer dos anos 1960 que o termo gradualmente se firmou, principalmente nos nomes de Emmanuel Le Roy Ladurie e Jacques Le Goff (HAR-PELED 2010, p. 2-3). Essa "ancoragem" da historiografia nos mares da antropologia e da etnologia 
se tornou perceptível na obra seminal de Le Roy Ladurie, Mountaillou. Apoiada em autores como Godelier, Bourdieu, Sahlins, Lévi-Strauss, entre tantos outros, ela demarcava novas possibilidades à análise das experiências humanas do passado, em uma confraria de historiadores e antropólogos (BENATTE 2007, p. 2-3).

No caso de Le Goff, entre as décadas de 1960 e 1970, existiu uma gradual inflexão à antropologia, sedimentada na criação do Groupe d'Anthropologie Historique de l'Occident Médievál em 1978 (HAR-PELED 2010, p. 3-4). Nota-se que, em 1977, no prefácio de Pour un Autre Moyen Age, o pesquisador destacou o papel crucial da etnologia em um diálogo profícuo com a história - o que Durkheim foi às gerações precedentes; Marcel Mauss o era a sua (LE GOFF 1993, p. 10-11).

Em 1977, Le Goff afirmou sua preferência pelo termo "antropologia histórica", no lugar de "etnologia histórica". Segundo o autor, a etnologia esteve circunscrita à concepção de um colonialismo europeu; enquanto a antropologia se voltava a um conhecimento abrangente das sociedades humanas. $O$ projeto dessa aproximação à ciência social vizinha configuraria, no campo da história, um saber distinto daquele elaborado pelas "classes dirigentes brancas" (LE GOFF 1993, p. 11).

Os fundamentos do giro antropológico se pautaram em uma descentralização da história - nas margens, essa não seria geocentrada ou etnocentrada. Se a medievalística francesa seguiu ou não esses caminhos, importa que, de algum modo, uma antropologia histórica do ocidente rompeu com a perspectiva de uma história nacional vigente. Tal percepção se constituiu em uma geração de historiadores influenciados pelo cenário do pós-guerra, mas, principalmente, pelos movimentos de descolonização e o "maio de 1968" (HAR-PELED 2010, p. 5-6).

Quando Le Goff traçou como um dos fundamentos de sua antropologia histórica do ocidente medieval o método comparativo, principalmente com o que ele chamou de 
"sociedades primitivas", ele alicerçou um distanciamento entre a Idade Média e o tempo presente. Primitivos e medievais se aproximavam justamente porque se distanciavam dos modernos (BASCHET 2016, p. 122-123). De modo similar, as elucubrações de Schmitt se pautaram em um método que afastava o historiador do cristianismo medieval de seu objeto de estudo, em um distanciamento entre "nós" e "eles": "o cristianismo medieval é uma cultura singular, mas o mesmo pode ser dito de qualquer outra cultura. Os cristãos são "como os outros" (SCHMITT 2014, p. 40).

No entanto, não nos restam dúvidas dos limites deste giro antropológico, ao menos em sua vertente francesa. Ao proporem outra história para além das fronteiras nacionais, estes historiadores reiteraram novos centrismos. No fim, suas histórias pouco se afastaram daquelas elaboradas pelas "classes dirigentes brancas", tal como aclamaram realizar. Vale lembrar que, para Misgav Har-Peled, a antropologia histórica se desenvolveu no cenário francês do pós-guerra como uma "contra-história" pautada pelas margens, defronte a uma história nacional e branca. Sobreposta no século XXI, ao confrontar problemas como a transculturalidade, a superação de um modelo centro/periferia e, principalmente, ao abandonar uma narrativa centrada no ocidente, na Europa e no cristianismo, segundo suas palavras, ela desencadearia em uma história mais dialógica daquilo que se compreende como "Ocidente" (HAR-PELED 2010, p. 8).

Quais seriam, então, os caminhos a uma história deseurocentrada, que objeta povos que circularam em uma espacialidade europeia? Os primeiros passos desse movimento se dão ao reconhecermos, conforme Eduardo Aubert, que a fratura conceitual instituída com o estabelecimento da modernidade, entre os séculos XVIII e XIX, alicerçava uma episteme na qual o Ocidente moderno seria contraposto, tanto em relação a um mundo não ocidental, como a América, quanto ao seu próprio passado pré-moderno. Assim, as nascentes ciências sociais fundadas na Europa do oitocentos 
se constituíram a partir desta triangulação entre um Ocidente moderno, um passado ocidental e um presente do não ocidente (AUBERT 2010, p. 1-2).

"Descolonizar" a Idade Média, nos dizeres de Jeffrey Cohen, incidiria em um processo de questionamento do caráter intermediário dessa temporalidade entre os antigos e os modernos, isto é, de questionamento de uma existência alicerçada no reflexo da modernidade (COHEN 2000, p. 6). Os alicerces do eurocentrismo não se encontravam apenas em sua posicionalidade espacial, mas também temporal, figurada na própria ideia da modernidade. Este "euromodernocentrismo" se organizava como uma espécie de epicentro da história, capaz de nomear e classificar outras realidades espaço-temporais, fossem elas uma "América Primitiva", uma "Grécia Antiga" ou uma "Europa Medieval". Uma fórmula de produção do conhecimento capaz de impor, por exemplo, a lógica moderna da religiosidade cristã à compreensão dos modos de crença ameríndios e cristãos pré-modernos.

Como vimos, as ressalvas de Jean-Claude Schmitt acerca da problemática de uma história religiosa da Idade Média se assentaram na existência de uma continuidade - aparente entre os modos de crença cristãos pré-modernos e modernos. Para Schmitt, esse era um dos pontos fulcrais ao exercício da medievalística: evitar essas "continuidades aparentes" que conectam seu tempo ao universo medieval e que acabam por nublar sua visão. E como historiadores, qual continuidade talvez nos fosse mais aparente que não a própria história?

\section{Um paradigma euro-moderno}

O medievalista Alain Guerreau, ao se aprofundar no que denominou uma "fratura" que distanciava modernos e prémodernos, acabou por delinear a impossibilidade da existência de historiadores antes do século XVIII. Impor essa categoria a personagens como Plutarco, Eusébio de Cesareia, e até mesmo Voltaire, incorreria em um erro. Não existia nestes autores, o 
que Guerreau entende como a pedra fundamental do ofício: a compreensão de que as sociedades humanas se transformam (GUERREAU 2002, p. 30).

Um movimento que, conforme Reinhart Koselleck, teve sua origem no distanciamento entre o espaço de experiências e o horizonte de expectativas, em um processo de aceleração do tempo, de tal modo que as mulheres e homens dos séculos XVIII e XIX cada vez menos percebessem ecos do passado em seus presentes e futuros. A emergência de conceitos como progresso e revolução incidiam em um olhar mais atento ao que se transformava do que ao que permanecia. Não que o termo história inexistisse antes do advento de um conceito moderno. Como demonstrou Koselleck, a "novidade" daquela altura foi a transformação das histórias em uma história, isto é, de uma noção plural à concepção de um singular coletivo, uma História, substantivo próprio, que pode abranger tanto a realidade quanto a forma de expressá-la, como em uma fusão da antiga distinção entre a res gestae e a historia rerum gestarum (KOSELLECK 2012).

Muito bem. Se a história, tal qual foi concebida na modernidade, inexistia anteriormente aos séculos XVIII e XIX, seria possível escrever uma história de algo que não existe? 0 problema é que a concepção dessa historiografia moderna se encerra em si mesma: ao mesmo tempo em que ela marcava a origem do conceito, ela se firmava como um "ponto arquimédico" capaz de definir o que é história ou não (SETH 2013, p. 175). Uma aporia que, como apontaram Santos, Nicodemo e Pereira, incide no seguinte questionamento: "sendo a história um produto da modernidade europeia, do período 1750-1850, é possível falar de fato em outras tradições historiográficas, nãoocidentais?" (SANTOS; NICODEMO; PEREIRA 2017, p. 174). E mais, a emendar essas palavras, é possível falar em tradições historiográficas não ocidentais ou pré-modernas?

Neste momento se faz essencial definirmos os contornos do que fazemos, quando afirmamos empreender uma história da historiografia. Essa, como realça Araujo, surgiu 
conjuntamente ao processo de estabelecimento da história em fins do século XIX. De tal modo que, sendo função primária, a história da historiografia visava à configuração de uma narrativa acerca das formas de escrever o passado, dos antigos aos modernos. Contudo, com a quebra de percepções lineares, como se uma determinada ciência pudesse ser concebida apenas através de continuidades, a história da historiografia se firmou como um meio de objetar as condições de produção do discurso histórico (ARAUJO 2006, p. 79-80).

Como uma subdisciplina da história, ela se volta ao estudo de "fenômenos historiográficos", indicados por Araujo, como os modos de historicidade, isto é, as experiências humanas do tempo. Ela não deve se circunscrever ao exame de uma história disciplinada - o exercício desta história da historiografia presume o que o próprio autor definiu como uma teoria da historicidade, uma teoria que fundamenta a natureza historiográfica de um dado objeto. Sua complexidade, porém, encontra-se justamente na capacidade de compreendermos as condições de emergência de um determinado tipo de história (ARAUJO 2013, p. 38-43).

Contudo, mesmo esse modelo de história da historiografia encontrou seus críticos, precisamente no que esses definiram como o caráter não universal da história. Sanjay Seth, nessa perspectiva, entendia que a história, como código baseado em uma determinada historicidade ocidental, era incapaz de "codificar passados não-ocidentais".

Nas palavras de Seth, quando os historiadores ocidentais escrevem sobre passados vinculados às suas identidades históricas, esses se defrontam com bruxas, dragões e milagres, ou seja, com um código distinto a uma observação racionalista. Porém, esse passado é compreendido no processo em que ele deixa de ser ele mesmo, isto é, no processo de dessacralização de uma sociedade que deixou de acreditar em bruxas, dragões e milagres e passou a escrever sobre elas, de modo a inseri-las em um viés racional. 
No processo de marcação de uma distância entre o objetopassado e o presente das práticas do historiador, essas constantemente se mesclavam. E aqui se encontraria a incapacidade de a história codificar os passados não ocidentais: "a história continua "encontrando o presente no seu objeto", mas não encontra "o passado na sua prática", pois o passado dos países não-ocidentais não é o passado da história" (SETH 2013, p. 178-179).

\section{Outras tradiçōes}

Ao seguirmos o modelo de uma história da historiografia que se instaura como um meio de analisar os modos de historicidade das sociedades humanas, incorremos na aporia de um saber incapaz de compreender a experiência do tempo em contextos pré-modernos ou não ocidentais. Seria necessário à execução de tal tarefa entender como outros grupos de costumes distintos dos nossos experimentavam o tempo de outra maneira: "outras épocas, outros costumes". A frase célebre do antropólogo Marshall Sahlins nos remete à possibilidade de outras formas de conceber a história. Em suas palavras, ordens culturais distintas possuem lógicas singulares de ação e de consciência histórica (SAHLINS 1990, p. 62). A historicidade moderna, apreendida como um fluxo do passado ao futuro mediado pelo presente, seria, portanto, apenas um dos modos de figurar o tempo. Outras ordens culturais possuiriam modos distintos de concebê-lo.

Sahlins definiu, desse modo, a urgência de uma antropologia da história pela sua capacidade de explodir o próprio conceito daquilo que compreendemos como história (SAHLINS 1990, p. 19). Um conceito que, como destacam Stephan Palmié e Charles Stewart, consolidou-se no mundo ocidental através do paradigma historicista moderno como a única maneira de observar o passado. Tal paradigma se pauta em princípios da lógica, da evidência e da verificabilidade pela prova, para citarmos apenas alguns de seus fundamentos. No entanto, por mais que tais princípios não sejam exclusivos 
ao historicismo moderno, outras culturas definiriam suas práticas singulares de historicização através de outros modos (PALMIÉ; STEWART 2016, p. 210).

Nas palavras de Palmié e Stewart, para além de uma história da historiografia ou uma filosofia da história, as abordagens etnográficas e antropológicas poderiam fornecer outras perspectivas sobre a relação das sociedades humanas com o passado, tanto por não privilegiarem textos escritos, quanto por um "olhar" não restrito a um paradigma moderno e ocidental. Uma abordagem que requer um novo vocabulário, afinal, a concepção de uma historiografia centrada na escrita invisibilizaria outras formas de experienciar o tempo. Ora, segundo os autores, a introdução de termos como "historicização" seriam capazes de abranger modalidades de produzir e representar o passado não restritivas a uma tradição moderna e ocidental fundamentada na escrituralidade (PALMIÉ; STEWART 2016, p. 207-226).

Em relação à observação de sociedades com distintos modos de historicização, o primeiro desses perigos é o de assumir essas lentes modernas - e seus princípios como a cronologia e a progressão - e invisibilizar esses outros modos de historicização. Um movimento que poderia incorrer na negação de modos locais e não ocidentais de se relacionar com o tempo - uma reiteração do colonialismo intelectual (STEWART 2016, p. 81). Conforme Palmié e Stewart, cabe à antropologia da história compreender como os modos de historicização são constituídos em sociedades não ocidentais e que, por sua vez, não se conformam aos moldes do historicismo moderno. Tal abordagem objetiva compreender como os diversos modos de historicização se tornavam convincentes e importantes em suas respectivas sociedades (PALMIÉ; STEWART 2016, p. 208-211).

Contudo, esta antropologia não pode se circunscrever somente a uma inquirição de outros modos de historicização deslegitimados e subordinados a uma historicidade moderna 
e ocidental. Essa antropologia precisa demonstrar como o próprio historicismo moderno é um fenômeno cultural e historicamente específico - seu exercício supõe a suspensão de um "etnocentrismo cronotópico" e do julgamento acerca desses outros modos de historicização. Mas qual o sentido da palavra "história" nesses estudos? Como reempregála sem incorrer nesse etnocentrismo cronotópico e na reiteração de um privilégio euro e modernocentrado (PALMIÉ; STEWART 2016, p. 225-226)?

O caminho traçado pelos autores busca uma conceituação simples e heurística da "história" capaz de abranger as formas de relação com o passado estabelecidas pela escrituralidade, pela oralidade, pela corporalidade, pelas afeições - uma "história" que não se restrinja ao historicismo moderno (PALMIÉ; STEWART 2016, p. 226). Para Stewart, no intuito de orientar essas pesquisas antropológicas, etnográficas e, acrescentaríamos aqui, históricas, a palavra deve significar aquilo que escolhemos que ela signifique. A história como uma categoria exógena, nessa perspectiva, não mais como um equivalente do historicismo moderno, abarcaria a diversidade espaço-temporal dos múltiplos modos de historicização (STEWART 2016, p. 83). Sem recair nas teias do anacronismo, o paradigma moderno de história não seria imputado a outras culturas - uma distinção que, em geral, as alça ao estatuto de uma não história. Trata-se de perceber que o paradigma moderno, assim como tantos outros paradigmas, compõe diferentes modos de historicização.

Ao assumirmos os conceitos de "história" e "historiografia" a partir de uma perspectiva modernocentrada e eurocentrada, esses seriam incapazes de apreender a diversidade espaçotemporal dos modos de se relacionar com 0 passado. Uma postura que insistiria em um privilégio de que a história só poderia existir em uma determinada posicionalidade espaço-temporal, ao passo que outras modalidades seriam circunscritas a uma não história. Assim, ao se afastarem 
de um paradigma historicista moderno, as experiências de historicização medievais eram neglicenciadas de um estatuto "historiográfico". Um olhar que busque descolonizar esta história ocidental deve assumir os fenômenos modernos e europeus enquanto cultural e historicamente localizados. O historicismo moderno e ocidental seria apenas um dentre tantos modos de historicização. O historicismo não pode ser um equivalente da história.

Santos, Nicodemo e Pereira, ao se confrontarem com a posicionalidade de termos como história e historiografia, e a incapacidade desses termos de compreenderem contextos não ocidentais - e, acrescentaríamos aqui, pré-modernos -, cogitaram dois caminhos possíveis. Por um lado, adotar os limites desses conceitos e restringir a história da historiografia a partir de uma tradição ocidental e moderna e, por outro, abarcar as múltiplas modalidades de historicização e colocar a estabilidade e relevância desta subdisciplina em questão (SANTOS; NICODEMO; PEREIRA 2017, p.181-182).

Aventar a primeira possibilidade incorreria ou na reiteração de uma caracterização na qual a história e a historiografia seriam um privilégio do mundo ocidental e moderno ou na edificação de uma espécie de "Torre de Babel" que instauraria uma incomunicabilidade entre as diversas pesquisas voltadas aos modos locais de produção e representação do passado. Por outro lado, a segunda alternativa considerada pelos historiadores supracitados, de fato, poderia tornar a história da historiografia restritiva e até mesmo irrelevante em relação às múltiplas histórias possíveis. Contudo, um caminho viável estaria em uma abertura proporcionada pelo chamado de Sahlins a um potencial destrutivo e criativo da abordagem antropológica da história. Destrutivo, pois seria capaz de romper com paradigmas consolidados na historiografia; criativo, porque seria capaz de substituí-los por modelos que harmonizassem a diversidade cultural no tempo e no espaço. A antropologia explodiria a história da historiografia não no intuito de extingui-la, mas de ampliar seus escopos. 
Nesse alargamento da história da historiografia, mais próxima de uma antropologia da história, quais seriam, então, os lugares nos quais se situariam as múltiplas realidades medievais, cristãs ou não?

Para a historiadora Gabrielle Spiegel, impor as categorias modernas de um realismo historiográfico à Idade Média incorreria em um erro justamente porque as fronteiras entre $o$ que poderia ser chamado de "real" ou "ficcional" no contexto medieval eram mais turvas e, em alguns casos, até inexistentes. Em sua perspectiva, a autora denota uma distinção essencial entre os parâmetros de uma historiografia moderna e uma historiografia medieval. Enquanto, na primeira, "conteúdo" e "fatos" se constituem como alicerces de uma vocação realista; a segunda se caracterizou justamente pelo emprego de um estilo realista permeado por um conteúdo que, aos olhos modernos, seria presumivelmente ficcional, como milagres, anjos e dragões (SPIEGEL 1997, p. xii).

Neste sentido, a produção historiográfica medieval deve ser concebida em seus próprios termos, sem imputar qualquer parâmetro alheio a ela, tal qual todo modo de produção e representação do passado deve ser compreendido. Como já dito, a seguir os modelos de uma antropologia da história, devemos entender como os modos de historicização de uma determinada sociedade se tornaram evidentes aos seus membros. Uma tarefa que se constitui necessária, pois a imposição de um paradigma moderno e historicista não apenas incorre em uma percepção errônea desses modos de historicização, mas também, na reiteração de um colonialismo intelectual que transforma esse mesmo paradigma em uma "ilha de história" cercada por um vasto oceano de "não histórias".

Como já vimos, as bases do historicismo moderno se encontrariam muito mais em uma posicionalidade espaçotemporal, figurada na Europa e na modernidade, do que simplesmente espacial. Tal posicionalidade se constituiu não somente em oposição a um mundo não ocidental, mas também frente a um passado pré-moderno. Fosse em um tom negativo 
que contrastava um tempo de luzes a um tempo de trevas ou nostálgico, que fazia do passado um berço mítico das origens, o mundo pré-moderno, como a própria terminologia sugere, não era moderno.

No exercício de uma antropologia histórica da história, a multiplicidade dessas modalidades de historicização prémodernas não seriam compreendidas como "primitivas" ou estágios embrionários e intermediários do que viria a ser a historicidade moderna. Em vez de pensarmos em continuidades ou descontinuidades que permitiriam ou não compreendermos os modos de historicização não ocidentais ou pré-modernos - fossem eles cristãos ou não -, deveríamos voltar nossos interesses à individualidade e alteridade dessas modalidades de produção e representação do passado. Reconhecer as existências destas outras tradições não ocidentais e prémodernas, mais do que negar sua relevância, enriqueceria a própria história da historiografia. 


\section{REFERÊNCIAS}

ARAUJO, Valdei Lopes de. História da historiografia como analítica da historicidade. História da Historiografia: International Journal of Theory and History of Historiograhy, v. 6 , n. 12, p. 34-44, 2013. DOI 10.15848/hh.v0i12.620. Disponível em: https://www.historiadahistoriografia.com. br/revista/article/view/620. Acesso em: 16 out. 2019.

ARAUJO, Valdei Lopes de. Sobre o lugar da história da historiografia como disciplina autônoma. Locus: Revista de História, v. 12, n. 1, p. 79-94, 2006. Disponível em: https:// periodicos.ufjf.br/index.php/locus/article/view/20629. Acesso em: 16 out. 2019.

AUBERT, Eduardo Henrik. L'anthropologie historique par le détour de la musicologie: une ethnomusicologie historique du Moyen Âge est-elle souhaitable?. L'Atelier du Centre de recherches historiques: Revue électronique du $\mathrm{CRH}$, v. 6 , n. 1, p. 1-13, 2010. Disponível em: https://journals. openedition.org/acrh/1916. Acesso em: 16 out. 2019.

BASCHET, Jérôme. Jacques Le Goff e o local correto das descontinuidades na História. Brathair: Revista de Estudos Celtas e Germânicos, v. 16, n. 2, p. 114-135, 2016. Disponível em: ppg.revistas.uema.br/index.php/brathair/ article/view/1248. Aceso em: 16 out. 2019.

BENATTE, Antonio Paulo. História e antropologia no campo da Nova História. Revista História em Reflexão, v. 1, n. 1, p. 1-25, 2007. Disponível em: http://ri.uepg. br/riuepg/bitstream/handle/123456789/523/ARTIGO_ HistoriaAntropologiaCampo.pdf?sequence $=1$. Acesso em: 16 out. 2019.

COHEN, Jeffrey J. Introduction: Midcolonial. In: COHEN, Jeffrey J. (org.). The postcolonial Middle Ages. New York: St. Martin's Press, 2000. p. 1-17. 
GUENÉE, Bernard. Histoire et culture historique dans I'Occident médiéval. Paris: Editions Aubier-Montaigne, 1980.

GUERREAU, Alain. EI Futuro de un Pasado: la Edad Media en el siglo XXI. Barcelona, Crítica, 2002.

HAR-PELED, Misgav. Décoloniser I'histoire occidentale: Les naissances politiques de l'anthropologie historique. L'Atelier du Centre de recherches historiques: Revue électronique du $\mathrm{CRH}$, v. 6, n. 1, p. 1-13, 2010. Disponível em: https://journals.openedition.org/acrh/1914. Acesso em: 16 out. 2019.

KOSELLECK, Reinhart. Futuro passado: contribuição à semântica dos tempos históricos. Tradução de Wilma Patrícias Maas; Carlos Almeida Pereira. Rio de Janeiro: Contraponto; Editora PUC-RIO, 2012.

LAKE, Justin. Currentapproachesto medieval historiography. History Compass, v. 13 , n. 13 , p. 89-109, 2015. DOI 10.1111/hic3.12222. Disponível em: https://onlinelibrary. wiley.com/doi/abs/10.1111/hic3.12222. Acesso em: 16 out. 2019.

LE GOFF, Jacques. Para um novo conceito de Idade Média: tempo, trabalho e cultura no Ocidente. Lisboa: Estampa, 1993.

PALMIÉ, Stephan; STEWART, Charles. Introduction: For an anthropology of history. HAU: Journal of Ethnographic Theory, v. 6, n. 1, p. 207-236, 2016. DOI 10.14318/ hau6.1.014. Disponível em: https://www.haujournal.org/ index.php/hau/article/view/hau6.1.014. Acesso em: 16 out. 2019. 
SANTOS, Pedro Afonso Cristovão dos; NICODEMO, Thiago Lima; PEREIRA, Mateus Henrique de Faria. Historiografias periféricas em perspectiva global ou transnacional: eurocentrismoem questão. Estudos Históricos, v. 30, n. 60, p. $161-186$, 2017. DOI 10.1590/s2178-14942017000100009. Disponível em: http://bibliotecadigital.fgv.br/ojs/index. php/reh/article/view/65456. Acesso em: 16 out. 2019.

SAHLINS, Marshall. Ilhas de História. Rio de Janeiro: Jorge Zahar, 1990.

SCHMITT, Jean-Claude. O corpo, os ritos, os sonhos, o tempo: ensaios de antropologia medieval. Petrópolis: Vozes, 2014.

SETH, Sanjay. Razão ou Raciocínio? Clio ou Shiva? História da Historiografia: International Journal of Theory and History of Historiograhy, v. 6, n. 11, p. 173-189, 2013. DOI 10.15848/hh.v0i11.554. Disponível em: https://www. historiadahistoriografia.com.br/revista/article/view/554. Acesso em: 16 out. 2019.

SPIEGEL, Gabrielle. The past as text: the theory and practice of medieval historiography. Baltimore: John Hopkins University Press, 1997.

STEWART, Charles. Historicity and Anthropology. Annual Review of Anthropology, v. 45, n. 1, p. 79-94, 2016. DOI 10.1146/annurev-anthro-102215-100249. Disponível em: https://www.annualreviews.org/doi/abs/10.1146/annurevanthro-102215-100249. Acesso em: 16 out. 2019. 
NOTA SOBRE O AUTOR

\section{Rodrigo Prates de Andrade}

andrade.rprates@gmail.com

Universidade Federal de Santa Catarina

Florianópolis

Santa Catarina

Brasil

\section{ENDEREÇO DE CORRESPONDÊNCIA}

\section{Rodrigo Prates de Andrade}

Universidade Federal de Santa Catarina

Departamento de História

Programa de Pós-Graduação em História

Trindade

88040900

Florianópolis, SC - Brasil

\section{FINANCIAMENTO}

Nenhum Financiamento foi declarado.

\section{CONFLITO DE INTERESSE}

Nenhum conflito de interesse declarado.

Copyright

2020

Historiografia:

International Journal

of Theory and History

of Historiography.

Este é um artigo

distribuído em Acesso

Aberto sob os termos

da Licença Creative

Commons Atribuição-

Não Com ercial -

SemDerivações 4.0

International. 